\title{
Enhanced western North Pacific tropical cyclone activity in May in recent years
}

\author{
Shibin Xu • Bin Wang
}

Received: 30 December 2012/Accepted: 14 August 2013/Published online: 29 September 2013

(C) The Author(s) 2013. This article is published with open access at Springerlink.com

\begin{abstract}
The tropical cyclone (TC) power dissipation index (PDI) in May over the western North Pacific (WNP) region shows a remarkable increase from the pre-1999 years (1979-1999) to the post-1999 years (2000-2011). Both increased TC numbers and enhanced TC intensity contributed to the change in the PDI. The averaged TC number in May increased from 1.05 per year in the pre1999 years to 1.75 per year in the post-1999 years. In particular, the number of intense typhoon goes up from 0.14 per year to 0.83 per year, implying a sharp increase of TC intensity. Examination of the large scale background circulation in May shows that the epochal increase of TC number is caused by a significant increase of the genesis potential index (GPI), which has increased by about $33 \%$ from the first (1979-1998) to the second (1999-2011) epoch over the $\mathrm{TC}$ genesis region $\left(110^{\circ} \mathrm{E}-160^{\circ} \mathrm{E}, 5^{\circ} \mathrm{N}-\right.$ $20^{\circ} \mathrm{N}$ ). The higher TC intensity is related to the increased maximum potential intensity and reduced TC ambient vertical wind shear in the second epoch. These decadal changes in background conditions over the WNP are the results of the enhanced summer monsoon in May over the both South Asia and South China Sea.
\end{abstract}

\footnotetext{
S. Xu

Physical Oceanography Laboratory, Ocean University of China, Qingdao 266100, China

S. Xu $\cdot$ B. Wang

International Pacific Research Center, University of Hawaii at Manoa, Honolulu, HI 96822, USA

B. Wang $(\bowtie)$

Department of Meteorology and International Pacific Research Center, University of Hawaii at Manoa, 1680 East West Road, POST 401, Honolulu, HI 96822, USA

e-mail: wangbin@hawaii.edu
}

Keywords Summer monsoon - Tropical cyclone . Decadal change

\section{Introduction}

The western North Pacific (WNP) has the most tropical cyclones (TC) all over the world, about one-third of all TCs over the globe occur in this region and cause serious property damage and loss of life. Therefore the variability of the TC activity over the WNP has received much attention. To a great extent, TC activities are affected by the large scale circulation (Harr and Elsberry 1995; Trenberth 2007) over the WNP, for instance, the low-level relative vorticity, the vertical wind shear (VWS), and the relative humidity $(\mathrm{RH})$ in the lower and middle troposphere are very important factors for TC activity (Gray 1968). The monsoon system, which is an important weather system over this region, can regulate the large-scale environment in which TCs are embedded and thus effects on the TC activities. On one hand, the summer monsoon system supplies low-level vorticity, mid-troposphere moisture that favors TC activity; on the other hand,the monsoon system may create a strong VWS that can depress TC activity in the monsoon regions (Lee et al. 1989; Evan and Camargo 2011).

The recently researches show that, as a result of the decadal shift of the summer monsoon onset (Kajikawa et al. 2012; Kajikawa and Wang 2012), the atmospheric circulation significantly changed in May and intensified TC activities in the recent decade have been found over the Arabian Sea (Evan et al. 2011; Wang et al. 2012). The TC activity over the WNP are expected to change significantly in May too. Tu et al. (2011) described an abrupt increase in intense typhoons over the WNP in May after the year 2000. 
They compared the sea surface temperature, upper-ocean heat content, tropospheric water vapor mid-troposphere $\mathrm{RH}$, the depth of $26^{\circ} \mathrm{C}$ isotherm and VWS and they suggest the mid-troposphere $\mathrm{RH}$ is the most important reason to the increased intense typhoon number. However, they didn't explain why the RH change in the recent years and how does it effect on TC activities. More details about the changes in TC activities need to be illustrated and the reasons of large-scale environmental indicators also need to be investigated to understand the TC activities.

In this paper, we try to describe more details of the increased TC number and enhanced TC intensity in May over the WNP in the recent years. The reason of the TC number change can be explained by the increased genesis potential index (GPI) and enhanced TC intensity is caused by larger maximum potential intensity (MPI) and weaker VWS. And finally, the effect of Asia summer monsoon system on the decadal changes in the large-scale thermal and dynamic conditions are investigated.

The data used are described in Sect. 2. The TC number and TC intensity changes in May are described in Sect. 3. The relationships between the enhanced TC activity and environmental factors are analyzed in Sect. 4. The impacts of decadal changes in the South China Sea (SCS) monsoon and South Asian (SA) monsoon on WNP TC activity are compared in Sect. 5. A summary of the results and some discussion are presented in Sect. 6.

\section{Data and methodology}

To investigate the features of TC activities, the TC power dissipation index (PDI; Emanuel 2005) for the period of 1979-2011 was calculated based on the best track TC data from the Joint Typhoon Warning Center (JTWC). The TC intensity are interpolated by 6-h records and only the TC with maximum surface wind greater than 34 knots (tropical storm) are considered.

The multi-level daily atmospheric data including winds, air temperature, relative and specific humidity, and the surface pressure with a $1.5^{\circ} \times 1.5^{\circ}$ spatial resolution derived from ERA interim (Dee et al. 2011) were used to calculate the TC genesis potential index (GPI; Emanuel and Nolan 2004) and investigate the large-scale environment factors for TC activity for the period of 1979-2011. The monthly precipitation data derived from the National Center for Environmental Prediction (NCEP) Climate Prediction Center Merged Analysis of Precipitation (CMAP; Xie and Arkin 1997) with $2.5^{\circ} \times 2.5^{\circ}$ spatial resolution are also used in this paper. The GPI index is defined as $\quad G P I=\left|10^{5} \eta\right|^{\frac{3}{2}}\left(\frac{H}{50}\right)^{3}\left(\frac{V_{\text {pot }}}{70}\right)^{3}\left(1+0.1 V_{\text {shear }}\right)^{-2}$, where $\eta$ is the absolute vorticity at $850 \mathrm{hPa}, H$ is the RH at
$700 \mathrm{hPa}, V_{\text {pot }}$ is the maximum potential intensity (MPI), and $V_{\text {shear }}$ is the VWS between 200 and $850 \mathrm{hPa}$. The VWS is defined as $V W S=\sqrt{(u 200-u 850)^{2}+(v 200-v 850)^{2}}$. The MPI is based on the theory of Emanuel (1988) and the calculation code is from Emanuel's website: ftp://texmex. mit.edu/pub/emanuel/TCMAX/.

\section{The enhanced tropical cyclone activity}

The PDI of TCs, the sum of the cubes of the maximum wind speed for the duration of the cyclone, reflects the combined information about the storm intensity and lifespan. Figure 1 shows that the PDI in May over the WNP has a significant increasing trend during the last 33 years. From the pre-1999 years to the post-1999 years, the mean PDI increased more than $120 \%$, from $0.9 \times 10^{7} \mathrm{~m}^{3} / \mathrm{s}^{3}$ to $2.2 \times 10^{7} \mathrm{~m}^{3} / \mathrm{s}^{3}$. The significance of the linear trend is over the $95 \%$ level by the Mann-Kendall test (Kendall 1975). However, this linear trend is largely due to the sudden change in 2000 , which is statistically significant at the $95 \%$ confidence level by the Lepage test (Lepage 1973). The increasing trend of storm number and PDI can also be found in the TC datasets from the Tokyo-Typhoon Center and Shanghai Typhoon Institute (not shown). This means that the TC activity in May was significantly enhanced during the past three decades. Because the PDI increase reflects changes in TC numbers, mean lifespan, and maximum wind speed, examination of each aspect is warranted.

Figure 2a shows the yearly averaged number of TCs, including tropical storms, typhoons, and intense typhoons in May for 1979-2011 based on the JTWC datasets. A tropical storm has a maximum surface wind greater than 34 knots $(17.5 \mathrm{~m} / \mathrm{s})$ and less than $63 \mathrm{knots}(32.4 \mathrm{~m} / \mathrm{s})$; a weak typhoon has a maximum surface wind greater than 64 knots $(32.9 \mathrm{~m} / \mathrm{s})$ and less than $113 \mathrm{knots}(58.1 \mathrm{~m} / \mathrm{s})$, which is

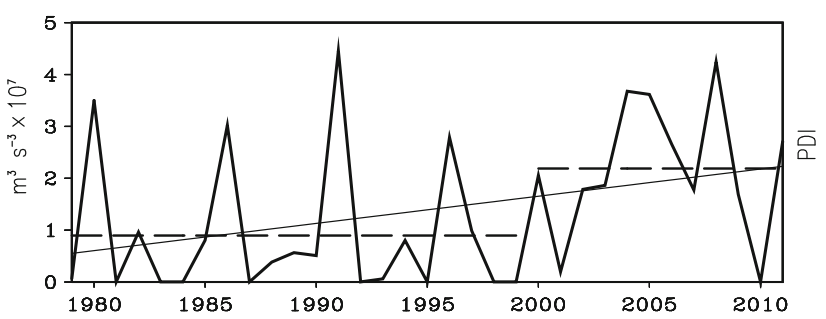

Fig. 1 PDI of May over WNP (including SCS) as a function of calendar year derived from JTWC best track data. The thin black line is the linear trend of PDI and the horizontal lines are the mean PDI of the two epochs. The significance of the linear trend is over the $95 \%$ level by the Mann-Kendall test. The sudden change in 2000 is statistically significant at the $95 \%$ confidence level by the Le Page test 
similar to category 1-3 hurricanes; and an intense typhoon has a maximum surface wind over 114 knots $(58.6 \mathrm{~m} / \mathrm{s})$, which is similar to category $4-5$ hurricanes. The mean TC number in May for the pre-1999 years is about 1.05 per year, including 0.45 tropical storms, 0.5 typhoons, and 0.15 intense typhoons. In contrast, the TC number in May for the post-1999 years goes up to 1.75 per year including 0.67 tropical storms, 0.25 typhoons, and 0.83 intense typhoons. The total numbers of TCs increased by $59 \%$. The difference between the TC numbers for the pre-1999 years and post-1999 years is statistically significant at the $90 \%$ confidence level by $t$ test. Notably, the number of intense typhoons has increased remarkably, meaning that the TC intensity has dramatically increased along with the total TS number in May. The difference between the intense typhoon numbers for the pre-1999 years and the post-1999 years is over the $99 \%$ significance level by $t$ test. However, the averaged TC lifespan in the pre-1999 years (8.6 days) is slightly longer than that in the post-1999 years (7.6 days), without a significant change (Fig. 2b).

The TCs' tracks in May for the pre-1999 years and the post-1999 years are shown in Fig. 3. Most TCs that formed in the WNP move to the north-west at the beginning of their lifespan and turn to the north-east around $15^{\circ} \mathrm{N}$. The TCs that formed in the SCS move to north-east during their entire lifespan. Although some TCs crossed Taiwan and the Philippine islands, few TCs made landfall on the Asian mainland in May. These tracks are consistent with the climatological mean steering flow in May (figure not shown).

More than $95 \%$ TCs genesis occurs in the region of $\left(110^{\circ} \mathrm{E}-160^{\circ} \mathrm{E}, 5^{\circ} \mathrm{N}-20^{\circ} \mathrm{N}\right)$, thus we define this region as the WNP TC genesis region. Most TCs got their lifetime maximum intensity (LMI) in the region of $\left(110^{\circ} \mathrm{E}-160^{\circ} \mathrm{E}\right.$, $\left.10^{\circ} \mathrm{N}-25^{\circ} \mathrm{N}\right)$, thus we defined this region as the TC

\section{a}

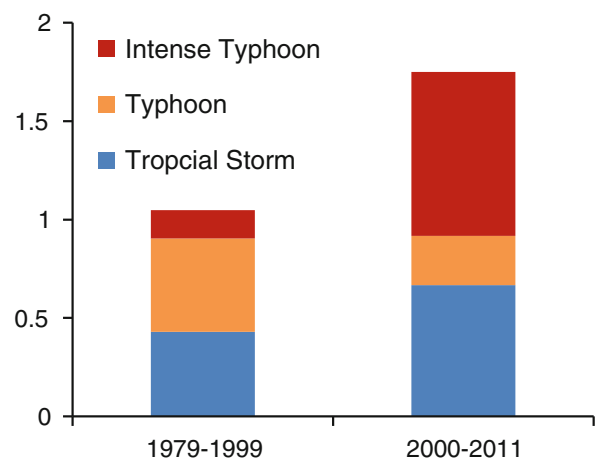

Fig. 2 Averaged TC numbers (a) and lifespan (b) in the pre-1999 years and the post 1999 years. A tropical storm has a maximum surface wind range from 35 knots to 63 knots; a weak typhoon has a maximum surface wind range from 64 knots to 112 knots; and an intense typhoon has a maximum surface wind greater than 113 knots. intensification region. The averaged genesis longitudes of TCs for the pre-1999 years and the post-1999 years are $140.2^{\circ} \mathrm{E}$ and $132.1^{\circ} \mathrm{E}$, respectively. The difference in the TC genesis longitude is statistically significant at the $90 \%$ confidence level by $t$ test. The westward shift of genesis
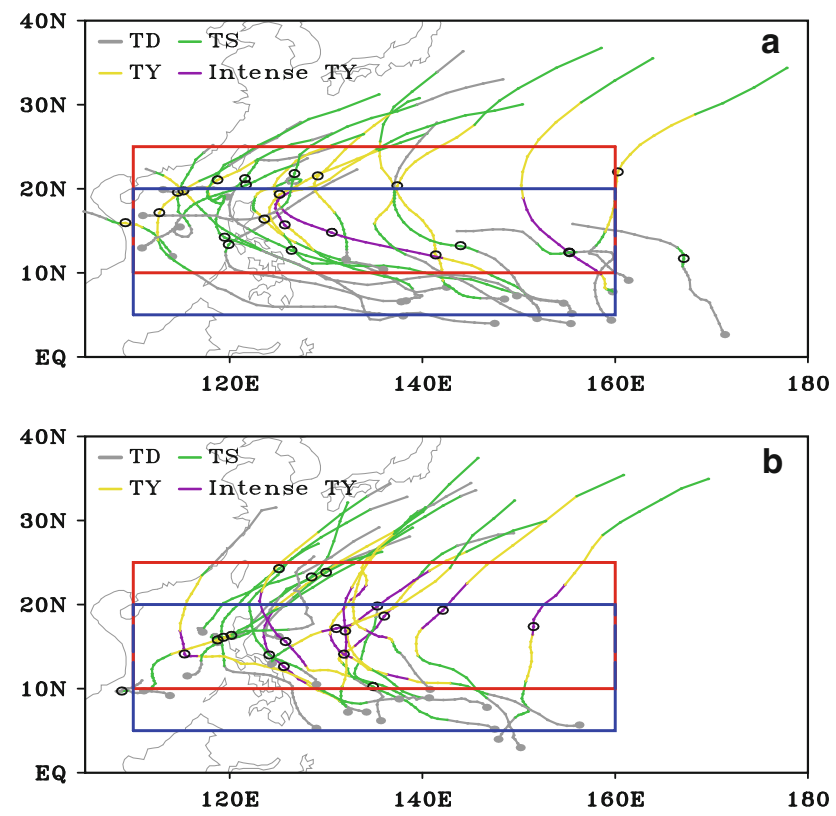

Fig. 3 a May TC over WNP of the pre-1999 years. The intensities of the TCs are indicated by colors. The gray dots are the genesis location of TCs and the open circles are the Life Maximum Intensity (LMI) location of TCs. The blue rectangle $\left(110^{\circ} \mathrm{E}-160^{\circ} \mathrm{E}, 5^{\circ} \mathrm{N}-20^{\circ} \mathrm{N}\right)$ is the $\mathrm{TC}$ genesis region. The red rectangle $\left(110^{\circ} \mathrm{E}-160^{\circ} \mathrm{E}, 10^{\circ} \mathrm{N}-25^{\circ} \mathrm{N}\right)$ is the TC intensification region. b May TC over WNP of the post-1999 years. The intensities of TCs are indicated by colors. The gray dots are the genesis location of TCs and the open circles are LMI location of TCs. The blue rectangle $\left(110^{\circ} \mathrm{E}-160^{\circ} \mathrm{E}, 5^{\circ} \mathrm{N}-20^{\circ} \mathrm{N}\right)$ is the TC genesis region. The red rectangle $\left(110^{\circ} \mathrm{E}-160^{\circ} \mathrm{E}, 10^{\circ} \mathrm{N}-25^{\circ} \mathrm{N}\right)$ is the TC intensification region

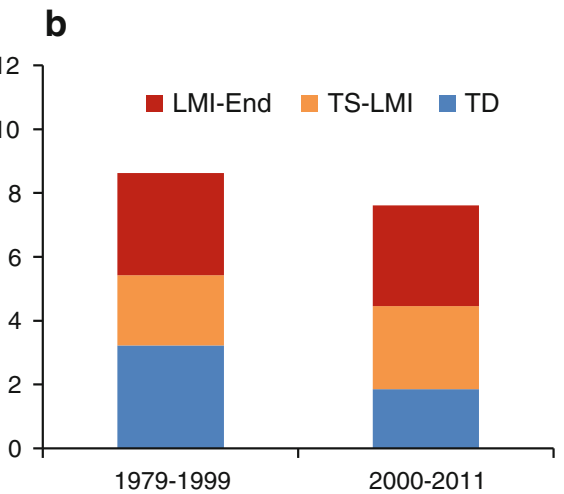

The difference of the TC numbers between the pre-1999 years and the post 1999 years is statistically significant at the $85 \%$ confidence level by $t$ test. The difference of the intense typhoon number is over the $99 \%$ significance level by $t$ test 
locations may reduce the TC lifespans. The mean LMI location of TCs are $131.4^{\circ} \mathrm{E}, 17.1^{\circ} \mathrm{N}$ in the pre-1999 years and $128.2^{\circ} \mathrm{E}, 16.9^{\circ} \mathrm{N}$ in the post- 1999 years and the standard deviation of LMI locations on longitudes are $16.0^{\circ}$ and $9.7^{\circ}$, indicating that the TCs' LMI locations had an insignificant westward shift and were more concentrated in the post-1999 years.

\section{The environmental factors affecting TC activity}

\subsection{The GPI}

To explain why there are more TCs over the WNP in May during the recent years, we examined the Genesis Potential Index (GPI), which can estimate the likelihood of TC genesis, over the WNP in May for the period 1979-2011. As shown in Fig. 4, the averaged GPI over the TC genesis region reveals a significant decadal shift in 1999. The averaged GPI before 1999 is 4.0 and its counterpart of the recent years is 5.3, the averaged GPI over the TC genesis region increased more than $32 \%$. The upward trend is over the $95 \%$ significance level by the Mann-Kendall test. The sudden change around 1999 is statistically significant at the $95 \%$ confidence level by the Le Page test. Such a decadal shift in GPI is generally consistent with the decadal change in TC activity. Because of the GPI is depend on the largescale circulations, which is more stable than TC activity, the epoch 1 (1979-1998) and epoch 2 (1999-2011) are defined based on the decadal change in GPI to analysis the large-scale indicators in the following parts.

Figure 5 shows the climatology GPI from 1979 to 2011 and the epochal difference of GPI (1999-2011 minus 1979-1998). The climatology GPI has a maximum center on the west side of Luzon Island and a secondary maximum center on the east side of Mindanao Island. From the first to the second epoch, the GPI has increased significantly over the subtropical (WNP) and slightly decreased east of $155^{\circ} \mathrm{E}$ (Fig. 5). This east-west dipole pattern implies that the maximum center of GPI shifted westward,

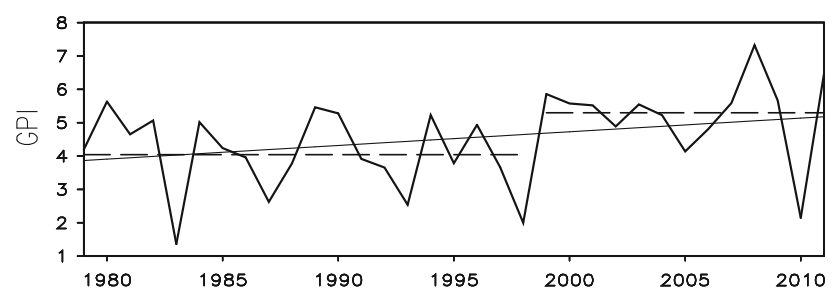

Fig. 4 GPI over the WNP TC genesis region $\left(110^{\circ} \mathrm{E}-160^{\circ} \mathrm{E}, 5^{\circ} \mathrm{N}-\right.$ $20^{\circ} \mathrm{N}$ ) in May as a function of calendar year. The significance of the linear trend is over the $95 \%$ significance level by the Mann-Kendall test. The sudden change around 1999 is statistically significant at the $95 \%$ confidence level by the Le Page test which explains why the TC genesis location shifted westward from the first to the second epoch. The increasing GPI in the SCS is mainly located between $10^{\circ} \mathrm{N}$ and $15^{\circ} \mathrm{N}$ on the south side of the climatology maximum center, implying a southward shift of TC activity in the SCS.

To investigate the importance of each of the four variables in the decadal shift of GPI, we calculated the GPI* by fixing three factors at their long-term climatology and allowing only one factor to vary. In this way, the contribution of each factor can be identified. Although the GPI is nonlinear product of the four factors, the relative importance of them can be evaluated by this method.

Figure 6 shows the epochal difference of GPI* induced by each parameter. Obviously, the GPI* of RH at $700 \mathrm{hPa}$ has the largest change among the four GPI*, indicating that the increase of GPI in the TC genesis region is mainly due to the change in $700 \mathrm{hPa} \mathrm{RH}$. The low-level vorticity is the second important variable for the GPI increase in the TC genesis region and it is the most important factor for the decreased GPI in the central tropical Pacific. The VWS reduced the GPI over the southern part of the SCS. The MPI also made a contribution to increasing GPI over the WNP.

Because the $\mathrm{RH}$ at $700 \mathrm{hPa}$ is the most important factor for the decadal change of the GPI, we examined its time series in May averaged over the TC genesis region (Fig. 7). The RH at $700 \mathrm{hPa}$ also has a decadal change from 1999 and its interannual variation is also similar to that of GPI (Fig. 4). The correlation between the time series of averaged GPI and RH is 0.9 , which is over the $99.9 \%$ significance level.

\subsection{The MPI and VWS}

The increased PDI was also due to the TC intensification. As mentioned previously, there are more intense typhoon occurrences in the WNP during the second epoch (Fig. 2),

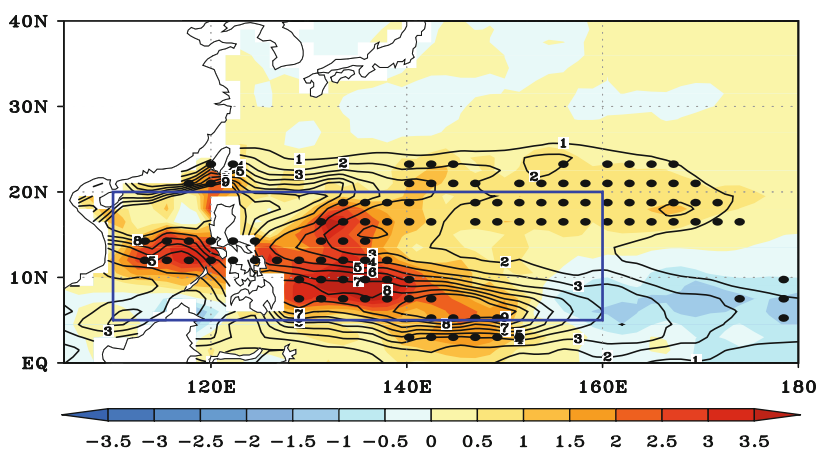

Fig. 5 The climatology (contour) and epochal difference (shading) (1999-2010 minus 1979-1998) of the GPI in May. The blue rectangle $\left(110^{\circ} \mathrm{E}-160^{\circ} \mathrm{E}, 5^{\circ} \mathrm{N}-20^{\circ} \mathrm{N}\right)$ is the TC genesis region. Stippled regions are for values significant at or above $95 \%$ confidence level 

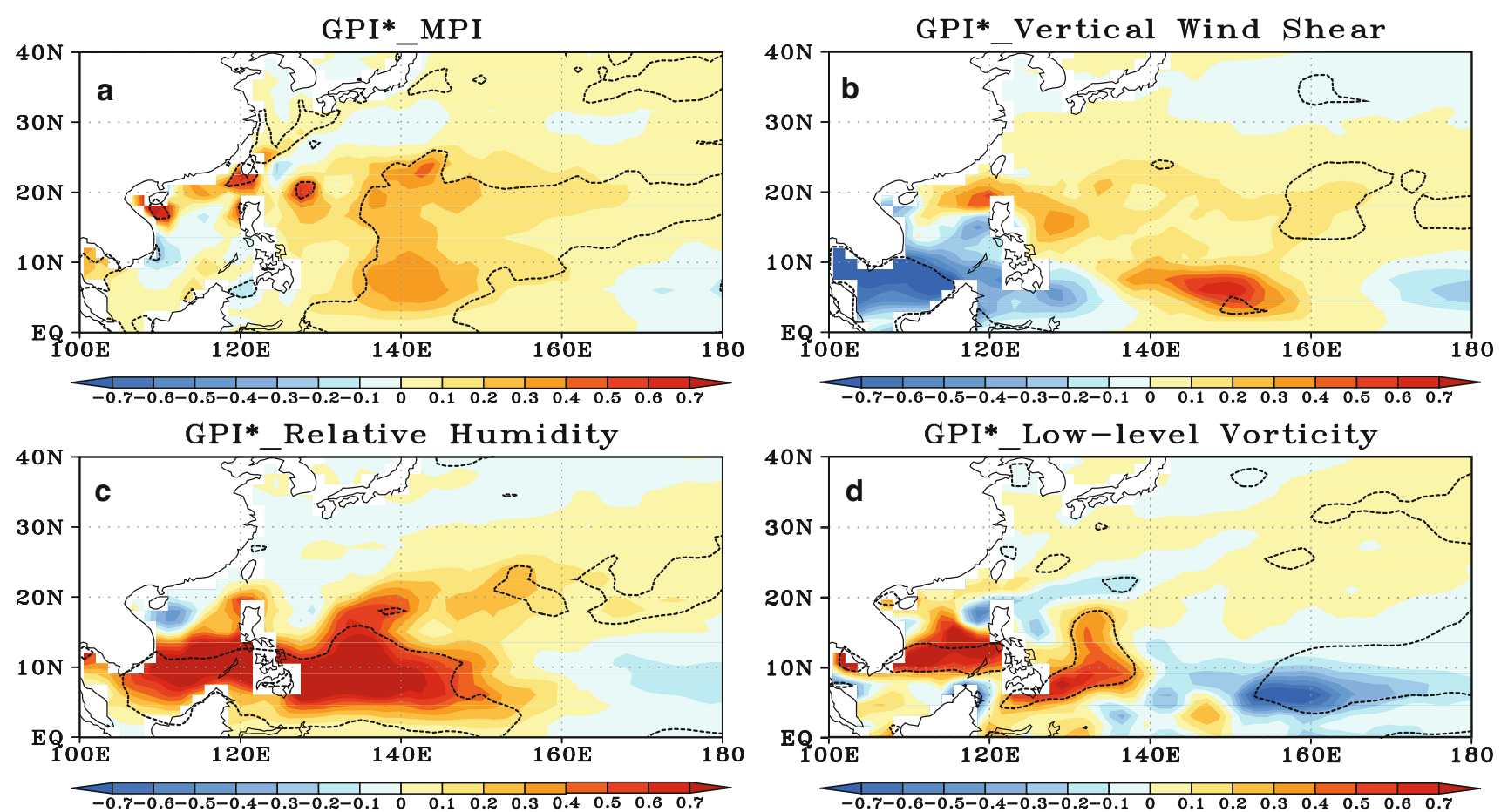

Fig. 6 The epochal difference of GPI* induced by a MPI, b VWS, c RH, and d Low-level Vorticity. When calculating the GPI* induced by a determined parameter, the other three parameters are replaced by

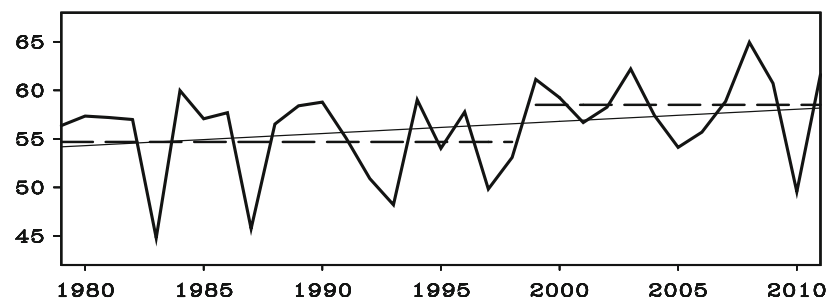

Fig. $7 \mathrm{RH}$ at $700 \mathrm{hPa}$ over the WNP TC genesis region $\left(110^{\circ} \mathrm{E}-\right.$ $160^{\circ} \mathrm{E}, 5^{\circ} \mathrm{N}-20^{\circ} \mathrm{N}$ ) in May as a function of calendar year. The significance of the linear trend is over the $90 \%$ significance level by the Mann-Kendall test. The sudden change around 1999 is statistically significant at the $95 \%$ confidence level by the Le Page test

thus the averaged TC intensity dramatically increases during the recent decade. Many studies suggest that both the internal dynamics and external forcing from environmental flow have the largest impact on TC intensification (Wang and Wu 2004; Zeng et al. 2007), thus TC intensity can be mainly explained by the MPI and the TC-ambient VWS. To find out why the TC intensity has an upward trend, we examined the MPI and TC ambient VWS over the TC intensification region.

On one hand, the decadal shift of VWS and MPI became more favorable for TC intensification from the first to the second epoch. As shown in Fig. 8a, the positive epochal difference (1999-2011 minus 1979-1998) of MPI dominates the TC intensification region while the epochal

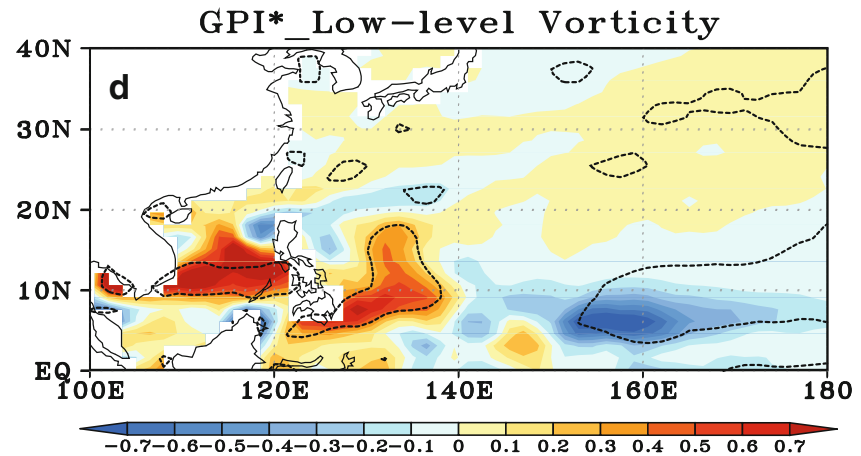

their climatology (1979-2011). The dashed lines are the $95 \%$ confidence level by $t$ test
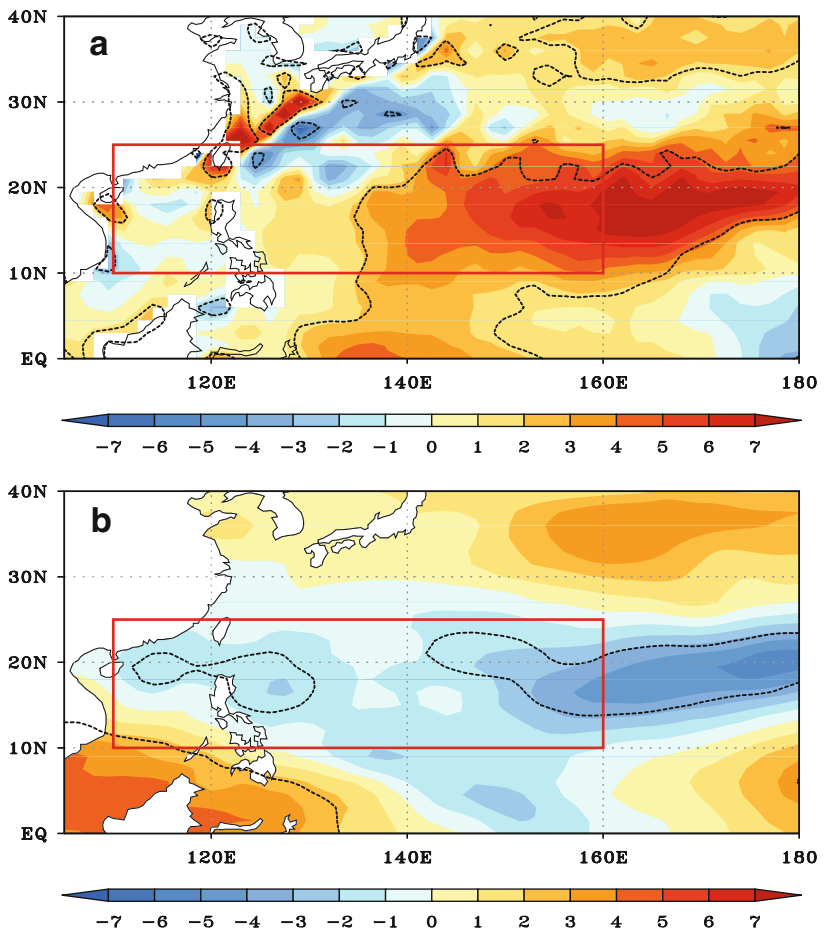

Fig. 8 The epochal difference (1999-2010 minus 1979-1998) of MPI (shading) and VWS (200-850 hPa) (contour) in May. The red rectangle $\left(110^{\circ} \mathrm{E}-160^{\circ} \mathrm{E}, 10^{\circ} \mathrm{N}-25^{\circ} \mathrm{N}\right)$ is the $\mathrm{TC}$ intensification region. The dashed lines are the $95 \%$ confidence level by $t$ test 

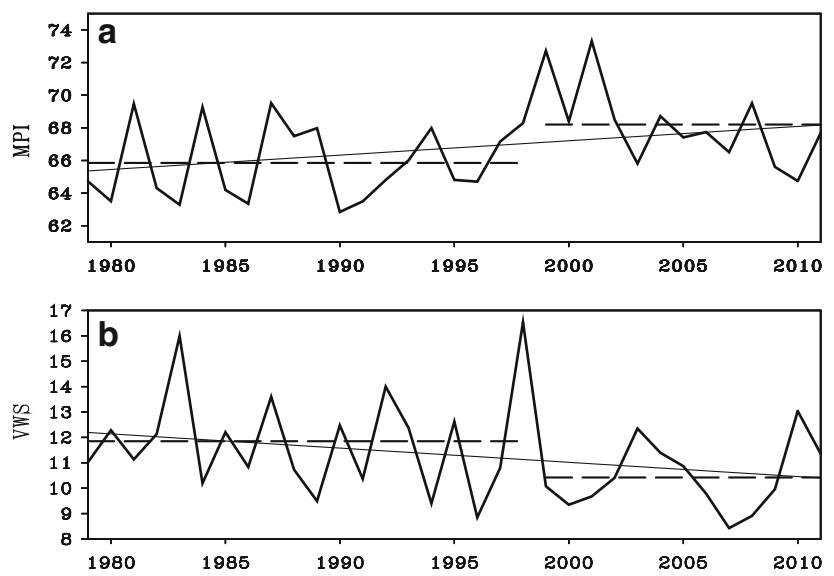

Fig. 9 a MPI and b VWS (200-850 hPa) over the WNP TC intensification region $\left(110^{\circ} \mathrm{E}-160^{\circ} \mathrm{E}, 10^{\circ} \mathrm{N}-25^{\circ} \mathrm{N}\right)$ in May. The significance of the linear trend is over the $90 \%$ (95\%) significance level by the Mann-Kendall test. The sudden change around 1999 is statistically significant at the $90 \%(98 \%)$ confidence level by the Le Page test

difference of the VWS is negative over the same region (Fig. 8b), especially over the eastern part of the TC intensification region.

We calculated the averaged MPI and VWS over the TC intensification region. The MPI has an upward linear trend in the past 33 years and shifts upward in 1999 (Fig. 9a). The VWS has a downward linear trend and has a downward decadal shift around 1999 (Fig. 9b). The significance of the linear trend is over the 95 and $90 \%$ significance level, respectively, by the Mann-Kendall test for the MPI and VWS. The sudden change around 1999 is statistically significant at the $98 \%$ confidence level for MPI and $90 \%$ confidence level for VWS by the Le Page test.

On the other hand, the shift in TC genesis locations tends to make the TCs occur in a region that has a larger MPI and smaller VWS. The climatological distribution of MPI and VWS are shown in Fig. 10. It is clear that the climatology MPI has two maximum centers. One is on the equator and the other is around the Philippine islands. There is no TC activity in the former one because of the lack of Coriolis effect, thus we focused on the latter one. The MPI decreases sharply on the north side of the maximum center and decreases more smoothly on the east side. Because the mean longitude of the TCs' LMI locations shifted from $131.4^{\circ} \mathrm{E}$ to $128.2^{\circ} \mathrm{E}$ and became more concentrated near the mean longitude from the first to the second epoch (Fig. 3), the TCs tend to have a larger ambient MPI. Especially in the SCS, the mean TC LMI location shifted from $18.1^{\circ} \mathrm{N}$ to $15.2^{\circ} \mathrm{N}$, thus the MPI of the TCs may have increased during their intensification in the second epoch. Because the VWS has its minimum center

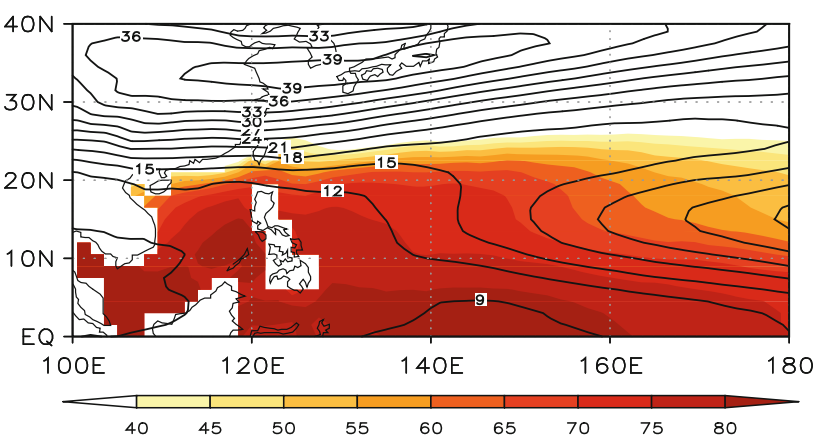

Fig. 10 The climatology of MPI (shading) and VWS (contour) in May (1979-2011)

around Philippine islands, the TCs tended to enjoy the weaker VWS at the same time.

As the result of decadal changes in MPI and VWS and the shift of TC tracks, WNP TCs experienced larger ambient MPI and smaller ambient VWS in the second epoch than in the first epoch. We calculated the TC ambient VWS and MPI in May over the WNP for the two epochs. The TC-ambient MPI and VWS are defined as the MPI and VWS at the location of each individual storm during its intensity increase from 34 knots $(17.5 \mathrm{~m} / \mathrm{s})$ to its LMI. To minimize the influence of the storm circulation on ambient flows, the MPI and VWS values for each TC are calculated during the period $48 \mathrm{~h}$ before its arrival. As shown in Fig. 11, the TC ambient VWS decreased about $1.6 \mathrm{~m} / \mathrm{s}$ and TC ambient MPI increased by about $7.5 \mathrm{~m} / \mathrm{s}$ from the first epoch to the second. The difference in VWS (MPI) between the two epochs is over the $95 \%$ (99.9\%) significance level by $t$ test. Thus, the TC intensity is larger in the second epoch and more intense TCs occurred during this time.

\section{The impacts of decadal changes in SCS monsoon and SA monsoon}

As mentioned above, the decadal shift in TC activities in May over the WNP depends on the changes in large-scale background conditions, such as RH at $700 \mathrm{hPa}$, VWS, and MPI. What causes the favorable environmental background in the second epoch? Those changes may be related to the decadal change of the summer monsoon system. However, previous studies show that the SCS summer monsoon has a decadal shift in the mid-1990s. The summer monsoon onset dates have been advanced and the mean westerly wind on $850 \mathrm{hPa}$ has been enhanced since 1994 (Kajikawa et al. 2012; Xiang and Wang 2013). There is a 5-year time lag between the decadal shift of the SCS monsoon and the decadal shift of the large scale environmental factors, 


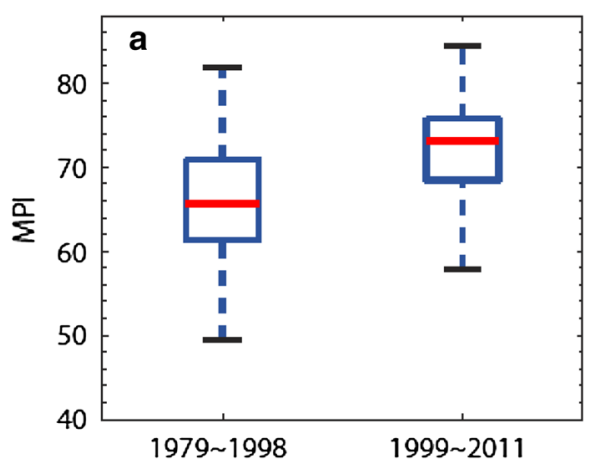

Fig. 11 The TC ambient $\mathbf{a}$ MPI and $\mathbf{b}$ VWS over the WNP in May of the two epochs. The TC-ambient MPI and VWS are defined as the MPI and VWS at the location of the storm during the TC intensity increase from 34 knots $(17 \mathrm{~m} / \mathrm{s})$ to its LMI. To decrease the influence
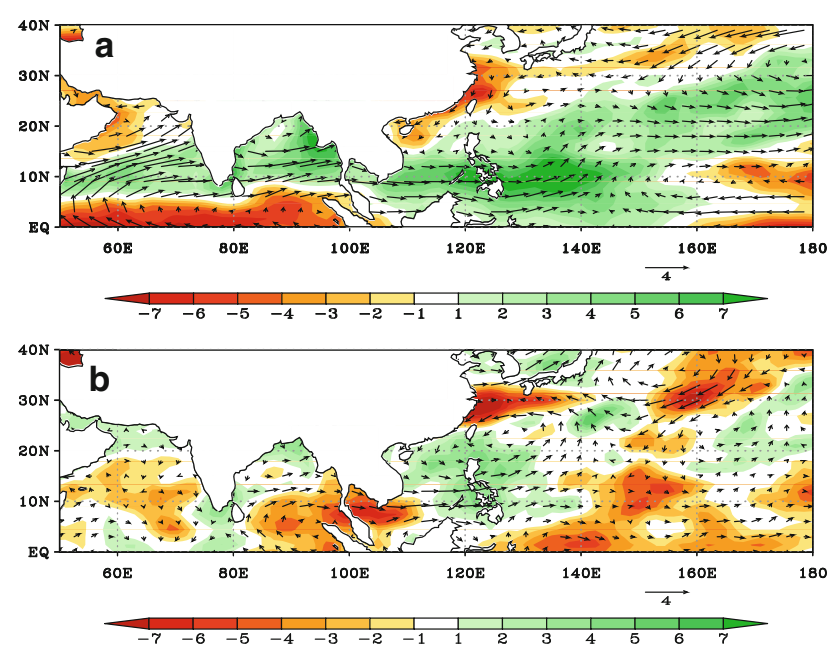

Fig. 12 a Epochal difference of $850 \mathrm{hPa}$ wind (vector) and $700 \mathrm{hPa}$ relative humidity (shading) in May from 1979-1998 to 1999-2011. b Epoch difference of $850 \mathrm{hPa}$ wind (vector) and $700 \mathrm{hPa}$ relative humidity (shading) in May from 1979-1993 to 1994-1998

indicating that the SCS summer monsoon is not the only decisive reason for the background change.

Figure 12a shows the epoch difference of the $850 \mathrm{hPa}$ wind and $700 \mathrm{hPa}$ RH between 1979-1998 and 1999-2011. The westerly wind in May is enhanced between $5^{\circ} \mathrm{N}$ and $15^{\circ} \mathrm{N}$, through the North Indian Ocean (NIO) to the WNP from the first to the second epoch. This pattern suggests that the Asian summer monsoon circulation has been enhanced in May. The RH at $700 \mathrm{hPa}$ also increased through the NIO to the WNP, which is the main contributor of the GPI increase from the first epoch to the second.

In contrast, the difference of the $850 \mathrm{hPa}$ wind between 1979-1993 and 1994-1998 has another pattern. The westerly wind on $850 \mathrm{hPa}$ only enhanced the southern part of the SCS from 1979-1993 to 1994-1998, suggesting that

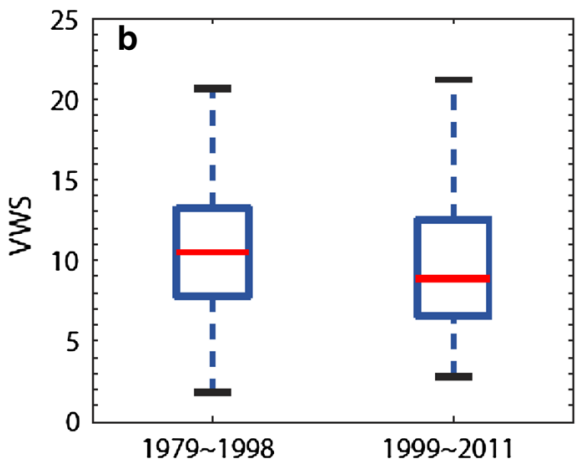

of the storm itself, MPI and VWS values for every TC are taken $48 \mathrm{~h}$ before the TC arrival. The difference of VWS (MPI) between the two epochs is over the $95 \%(99.9 \%)$ significance level by $t$ test
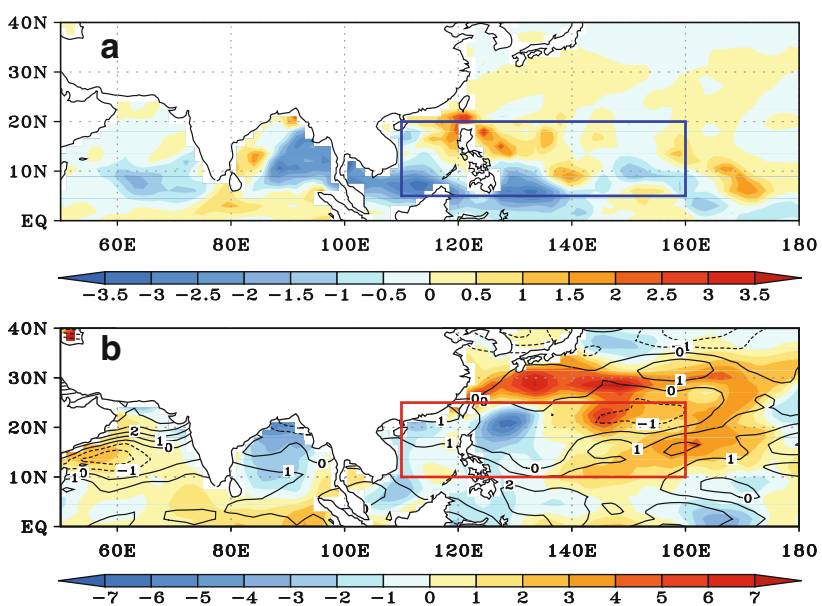

Fig. 13 The epochal differences of a GPI and b VWS (contour) and MPI (shading) from 1979-1993 to 1994-1998. The blue rectangle $\left(110^{\circ} \mathrm{E}-160^{\circ} \mathrm{E}, 5^{\circ} \mathrm{N}-20^{\circ} \mathrm{N}\right)$ is the $\mathrm{TC}$ genesis region and the red rectangle $\left(110^{\circ} \mathrm{E}-160^{\circ} \mathrm{E}, 10^{\circ} \mathrm{N}-25^{\circ} \mathrm{N}\right)$ is the $\mathrm{TC}$ intensification region

the SCS monsoon changes in 1994-1998 are just local phenomena. There is no significant change in the $850 \mathrm{hPa}$ wind over the NIO and most areas of the NIO are dryer than the previous epoch. This implies that the local westerly wind change in SCS cannot supply enough water vapor to the WNP without the help of upstream moisture transport. Thus, from 1979-1993 to 1994-1998 the RH at $700 \mathrm{hPa}$ did not have a significant increase over the WNP (Fig. 12b). As a result, the GPI over the WNP TC genesis region did not change significantly during 1994-1998 (Fig. 13a). At the same time, neither MPI nor VWS changed significantly over the TC intensification region (Fig. 13b).

As a result, although the SCS monsoon provided an enhancing effect in May of 1994-1998, TC activity did not increase. This is in contrast to after 1999 when both SA and SCS summer monsoons provided enhancement. The 
a
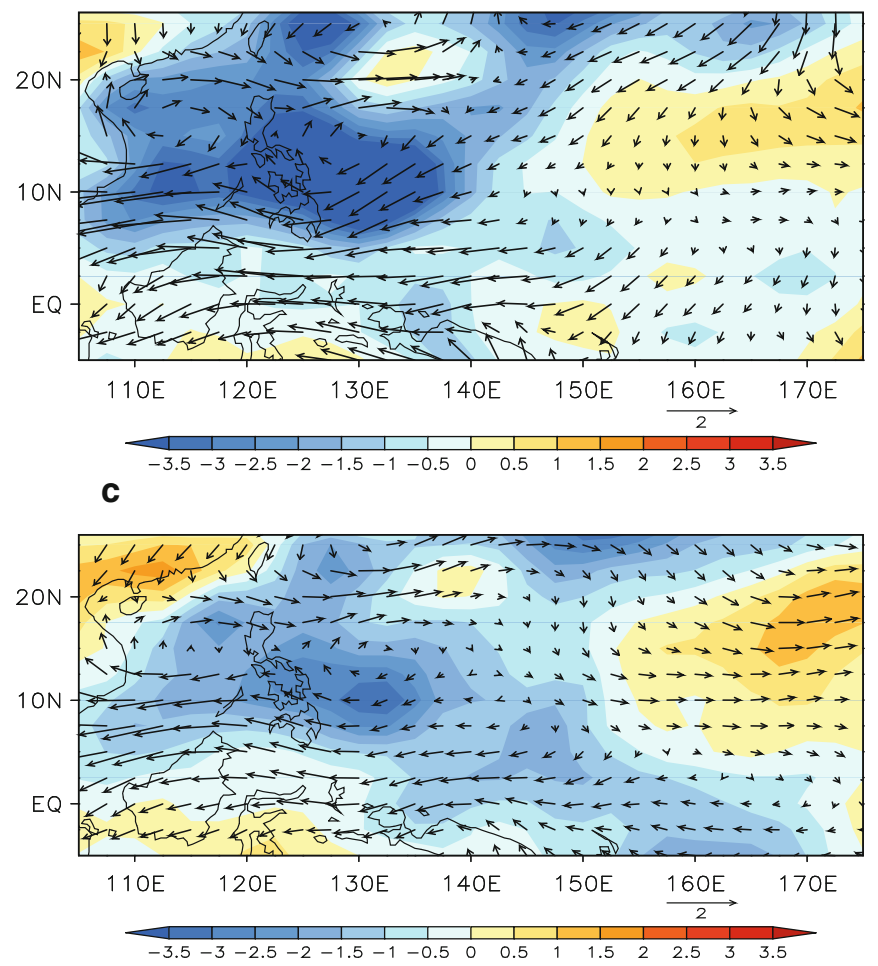

Fig. 14 a The $850 \mathrm{hPa}$ horizontal wind and eddy kinetic energy (EKE) in May of 1999 after 30-90 days band pass filter and $\mathbf{b}$. The $850 \mathrm{hPa}$ zonal wind (solid line) averaged over the region $\left[110^{\circ} \mathrm{E}-\right.$

enhancing effect of a large scale monsoon westerly can provide circulation conditions that are favorable enough to enhance TC activity through their cooperation. Thus both the SA and SCS monsoons are important for WNP TC activity in May.

\section{Summary and discussion}

Our results demonstrate that the TC PDI in May over the WNP region has remarkably increased after the year 2000 . The PDI went up from $0.9 \times 10^{7} \mathrm{~m}^{3} / \mathrm{s}^{3}$ per year to $2.2 \times 10^{7} \mathrm{~m}^{3} / \mathrm{s}^{3}$ per year with a significant decadal shift in 2000. Both the increased TC number and TC intensity contributed to the change in the PDI. The averaged TC number in May is 1.05 per year in the pre-1999 years (1979 1999) and 1.75 per year in the post-1999 years $(2000 \sim 2011)$. The number of intense typhoons goes up from 0.14 per year to 0.83 per year, implying an abrupt increase in TC intensity. The decadal change in TC number is caused by the significant change in the ambient GPI, which have a decadal shift in 1999 and increased about one third from the first to the second epoch over the TC genesis region $\left(110^{\circ} \mathrm{E}-160^{\circ} \mathrm{E}, 5^{\circ} \mathrm{N}-20^{\circ} \mathrm{N}\right)$. The increase in $\mathrm{TC}$ intensity tends to be caused by increased ambient MPI and

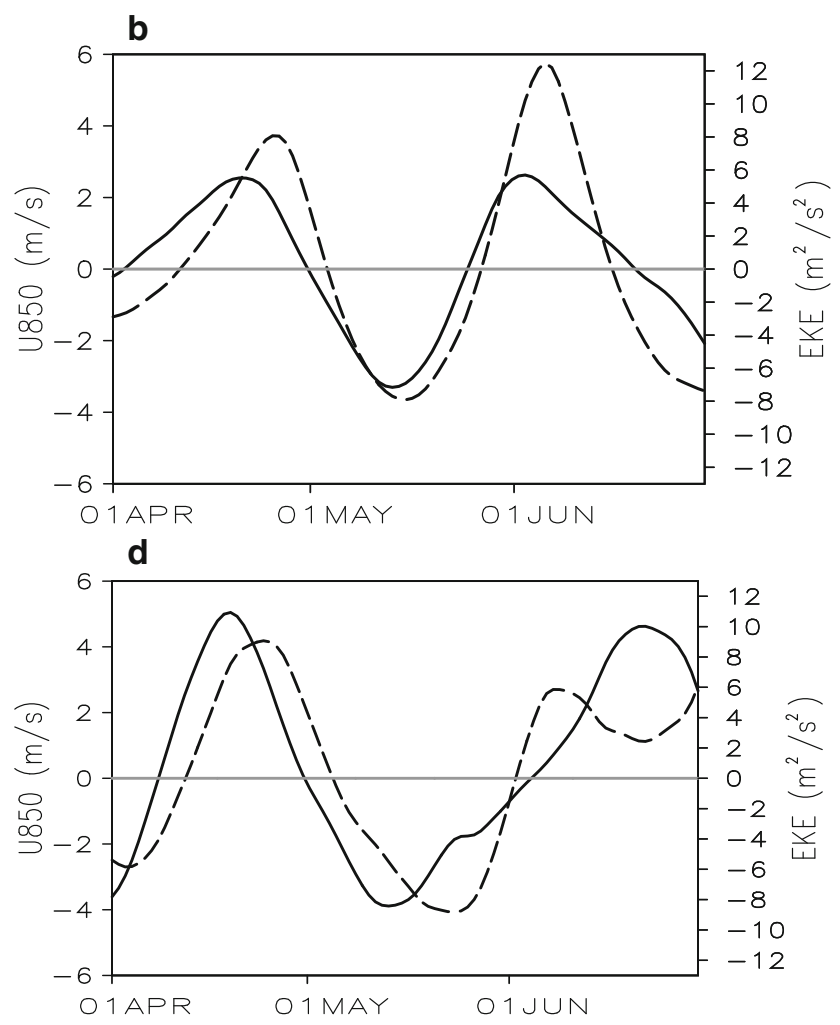

$\left.150^{\circ} \mathrm{E}, 5^{\circ} \mathrm{S}-10^{\circ} \mathrm{N}\right]$ and the EKE (dashed line) averaged over the region $\left[110^{\circ} \mathrm{E}-160^{\circ} \mathrm{E}, 5^{\circ} \mathrm{S}-20^{\circ} \mathrm{N}\right] . \mathbf{c}$ and $\mathbf{d}$ are the same as $\mathbf{a}$ and $\mathbf{b}$ but an ensemble of the year 1981, 1984, 1999 and 2001

decreased ambient VWS in the second epoch. The decadal changes in background conditions over WNP seem to be the result of the enhanced summer monsoon in May during the second epoch. Both the SA summer monsoon and CSC summer monsoon are important in this process.

It should be noted that the decadal shift in GPI and large-scale environmental factors occur in 1999 while PDI changed since 2000. Although the GPI in May 1999 is higher than other years, there was no tropical cyclone genesis in that month. The most possible reason may be the lack of perturbations which trigger storm formations during that month due to the easterly (dry) phase of the MaddenJulian Oscillation (MJO). MJO can modulate the TC activity on the intraseasonal time scale obviously through change the perturbations (eddy kinetic energy, EKE) (Liebmann et al. 1994; Maloney and Hartmann 2001), especially in May and June the intraseasonal oscillation can synchronously influence most TC genesis over the WNP (Huang et al. 2011). In May 1999, the WNP is controlled by a typical easterly phase of MJO, and this phase accidently persists the whole May (Fig. 14a, b). The easterly wind reduce disturbance over the WNP (Maloney and Dickinson 2003). Thus, the absence of TC may due to the lack of disturbances. In short, this problem is mainly due to the fact that we are looking for only 1 month in each year, 
and the 30 days period can be affected by MJO cycle, that is why the decadal shift in PDI did not occur in 1999. We also find other 3 years $(1981,1984$, and 2001) are similar to 1999 , which have relative higher GPI and extremely low PDI. All of them show easterly wind in tropical western Pacific and negative EKE over the WNP (Fig. 14c, d).

Xiang and Wang (2013) suggested that the root cause of this recent decadal shift in the Asian summer monsoon may be attributed to the mean state change in the Pacific basin. While Zhu et al. (2011) mentioned that the Pacific Decadal Oscillation (PDO), which shift from warm phase to cold phase in 1999, induce a decadal change in East China rain belt shift. At the same time, the WNP local SST tend to be warmer in the cold PDO phase, and the warmer SST may contribute to increase in MPI. That is one of the important reasons of the enhanced TC activity. Although the causes and mechanisms of the PDO change is not clear until now, the effect of PDO on the environment circulation change cannot be ruled out.

For further, we speculate that the changes in the Asian summer monsoon provide a favorable environment for enhanced TC activity, however, some other possible relationship may exist between TC activity and the monsoon circulation. Kajikawa and Wang (2012) argued that the TC activity might affect large scale circulation and trigger the summer monsoon onset during the transitional phase from spring to summer. The interaction between the large scale circulation and synoptic processes need further investigation.

Acknowledgments The authors acknowledge support of this study by China Scholarship Consul (CSC), NASA project (NNX09AG97G), the Global Research Laboratory (GRL) Program from the Ministry of Education, Science and Technology (MEST), and the International Pacific Research Center (IPRC), which is partially sponsored by JAMSTEC. This is publication 9001 of the School of Ocean and Earth Science and Technology and International Pacific Research Center Publication 1009.

Open Access This article is distributed under the terms of the Creative Commons Attribution License which permits any use, distribution, and reproduction in any medium, provided the original author(s) and the source are credited.

\section{References}

Dee DP, Uppala SM, Simmons AJ et al (2011) The ERA-interim reanalysis: configuration and performance of the data assimilation system. Q J R Meteorol Soc 137:553-597. doi:10.1002/qj. 828

Emanuel K (1988) The maximum intensity of hurricanes. J Atmos Sci 45:1143-1155

Emanuel K (2005) Increasing destructiveness of tropical cyclones over the past 30 years. Nature 436:686-688. doi:10.1038/ nature 03906
Emanuel K, Nolan DS (2004) Tropical cyclones and the global climate system. Paper presented at 26th conference on hurricanes and tropical meteorology, Am. Meteorol. Soc., Miami, Fla

Evan AT, Camargo SJ (2011) A climatology of Arabian Sea cyclonic storms. J Clim 24:140-158

Evan AT, Kossin JP, Chung CE, Ramanathan V (2011) Arabian Sea tropical cyclones intensified by emissions of black carbon and other aerosols. Nature 479:94-98. doi:10.1038/nature 10552

Gray WM (1968) Global view of the origin of tropical disturbances and storms. Month Weather Rev 96:669-700

Harr PA, Elsberry RL (1995) Large-scale circulation variability over the tropical western North Pacific. Part I: spatial patterns and tropical cyclone characteristics. Mon Weather Rev 123: 1225-1246

Huang P, Chia C, Huang R (2011) Seasonal modulation of tropical intraseasonal oscillation in tropical cyclone genesis in the western North Pacific. J Clim 15:6339-6352

Kajikawa Y, Wang B (2012) Interdecadal change of the South China Sea summer monsoon onset. J Clim 25:3207-3218

Kajikawa Y, Yasunari T, Yoshida S, Fujinami H (2012) Advanced Asian summer monsoon in recent decades. Geophys Res Lett 39:L03803. doi:10.1029/2011GL050540

Kendall MG (1975) Rank correlation methods, 4th edn. Charles Griffin, London

Lee CS, Edson R, Gray WM (1989) Some large-scale characteristics associated with tropical cyclone development in the North Indian Ocean during FGGE. Mon Weather Rev 117:407-426

Lepage Y (1973) A table for a combined Wilcoxon Ansari-Bradley statistic. Biometrika 60:113-116

Liebmann B, Hendon H, Glick J (1994) The relationship between tropical cyclones of the western Pacific and Indian Oceans and the Madden-Julian Oscillation. J Meteor Soc Jpn 72:401-412

Maloney E, Dickinson M (2003) The intraseasonal oscillation and the nergetics of summertime tropical western North Pacific synopticscale disturbances. J Atmos Sci 60:2153-2168

Maloney E, Hartmann D (2001) The Madden-Julian Oscillation, barotropic dynamics, and North Pacific tropical cyclone formation. Part I: observations. J Atmos Sci 58:2545-2558

Trenberth KE (2007) Warmer oceans, stronger hurricanes. Sci Am 297:44-51. doi:10.1038/scientificamerican0707-44

Tu JY, Chou C, Huang P, Huang R (2011) An abrupt increase of intense typhoons over the western North Pacific in early summer. Environ Res Lett 6:034013. doi:10.1088/1748-9326/6/3/034013

Wang Y, Wu CC (2004) Current understanding of tropical cyclone structure and intensity changes-a review. Meteor Atmos Phys 87:257-278. doi:10.1007/s00703-003-0055-6

Wang B, Xu S, Wu L (2012) Intensified Arabian Sea tropical storms. Nature 489:E1-E2. doi:10.1038/nature11470

Xiang B, Wang B (2013) Mechanisms for the advanced Asian Summer Monsoon onset since the mid-to-late 1990s. J Clim 26:1993-2009. doi:10.1175/JCLI-D-12-00445.1

Xie P, Arkin PA (1997) Global precipitation: a 17-year monthly analysis based on gauge observations, satellite estimates, and numerical model outputs. Bull Am Meteor Soc 78:2539-2558

Zeng Z, Wang Y, Wu CC (2007) Environmental dynamical control of tropical cyclone intensity - an observational study. Mon Wea Rev 135:38-59

Zhu Y, Wang H, Zhou W, Ma J (2011) Recent changes in the summer precipitation pattern in East China and the background circulation. Clim Dyn 36:1463-1473 